\title{
RANCANGAN RUANG PENGERING BERBASIS ERGONOMI MENURUNKAN KELUHAN MUSKULOSKELETAL PERAJIN IKAN
}

\author{
I Gede Bawa Susana* \\ Teknik Mesin F.T. Universitas Mataram, Jl. Majapahit No. 62 Mataram, Nusa Tenggara Barat, \\ 83125 \\ *Email : bawa.mech@yahoo.co.id
}

\begin{abstract}
With traditional fish drying process, most possible can cause an unhealthy working posture, such as a squatting action. As a consequence, worker will suffer a musculoskeletal disorders because of not ergonomic tools and bad working posture. Without ergonomics working procedures was found that the average of musculoskeletal complaints after working is $52.25 \pm 1.03$. To solve this ccomplaints, a drying chamber based ergonomics design was built in order to reduce musculoskeletal disorders. Dimensions of the drying chamber were based on anthropometric data of fish craftsmen and the material of drying chamber was by the participatory method. Test was performed on 20 samples and the result showed that the mean rate of musculoskeletal complaints after working is $38.30 \pm 1.30$. The ergonomic based design for drying camber application can reduce the musculoskeletal complaints up to $26.7 \%$.
\end{abstract}

Keywords: ergonomics, drying, musculoskeletal

\section{PENDAHULUAN}

Proses pengeringan ikan khususnya dalam skala rumah tangga atau home industry masih dilakukan secara tradisional yaitu menjemur di bawah terik matahari. Proses penjemuran menggunakan terpal atau anyaman bambu yang diletakkan di halaman rumah, pinggir jalan bahkan di atas atap rumah.

Proses pengeringan ikan secara tradisional dilakukan dengan sikap kerja jongkok, jongkok sambil bergeser, memutar, dan membungkuk seperti disajikan pada Gambar 1. Hal ini merupakan sikap kerja tidak alamiah. Adiputra (2004) menyatakan bahwa sikap kerja tidak alamiah menyebabkan adanya gerakan otot yang tidak seharusnya terjadi serta pemborosan energi, sehingga menimbulkan risiko kelelahan dan cedera otot.

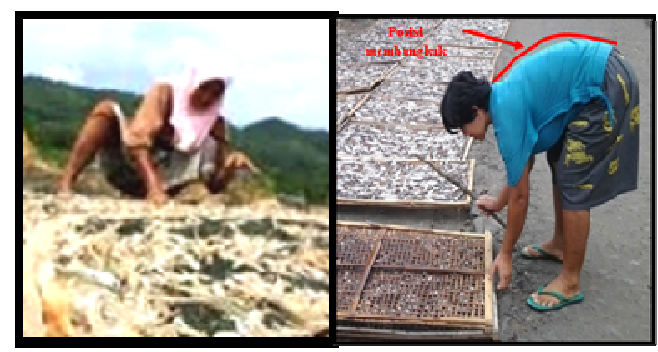

Gambar 1. Sikap kerja pekerja mengeringkan iKan
Sikap kerja tidak alamiah merupakan kondisi dengan gerakan tubuh menjauhi posisi alamiah atau posisi normal dalam melakukan pekerjaan atau aktivitas. Sikap kerja tidak alamiah seperti pada Gambar 1 disebabkan karakteristik alat kerja tidak sesuai dengan kemampuan dan keterbatasan pekerja, jadi kurang memperhatikan prinsipprinsip ergonomi yang pada akhirnya menimbulkan keluhan muskuloskeletal.

Keluhan sistem muskuloskeletal adalah keluhan pada bagian-bagian otot rangka yang dirasakan seseorang mulai dari keluhan sangat ringan sampai sangat sakit. Apabila otot menerima beban statis secara berulang dan dalam waktu lama menyebabkan keluhan berupa kerusakan pada sendi, ligamen, dan tendon. Keluhan hingga kerusakan ini yang diistilahkan sebagai keluhan musculoskeletal disorders (MSDs) atau cedera pada sistem muskuloskeletal (Kroemer dan Grandjean, 2000). Menurut Susila (2002), keluhan muskuloskeletal dapat terjadi hampir pada semua jenis pekerjaan baik dalam kategori ringan, sedang, berat, dan amat berat.

Berdasarkan penelitian pendahuluan yang dilakukan pada para wanita perajin ikan diperoleh rerata skor keluhan muskuloskeletal $51,5 \pm 5,89$. Rerata skor ini termasuk kategori tingkat risiko sedang atau diperlukan tindakan perbaikan (Tarwaka, 2011). Menurut Pheasant dan Haslegrave (2006), bahwa reaksi keluhan muskuloskeletal terjadi sebagai dampak dari sikap kerja membungkuk. Bridger (2003) menyatakan 
bahwa sekitar 30\% cedera otot skeletal bagian belakang disebabkan sikap kerja membungkuk dan memutar, sehingga ikut terputarnya tulang belakang.

Cedera atau keluhan pada otot dan persendian atau keluhan muskuloskeletal sebagai akibat dari peralatan kerja dan aktivitas fisik yang dilakukan di tempat kerja yang tidak ergonomis. Menurut Wignjosoebroto (2011), problematik kerja yang sering dialami manusia seperti keluhan muskuloskeletal akan bisa dicegah melalui pendekatan ergonomi.

Ergonomik atau ilmu ergonomi adalah ilmu yang mempelajari karakteristik meliputi kemampuan atau kapabilitas, keterbatasan, motivasi, dan tujuan manusia dalam menentukan desain yang tepat bagi lingkungan kerja dan kehidupan pekerja sehari-hari (Plog dan Quinlan, 2002). Ergonomi atau sering disebut human engineering didefinisikan sebagai perancangan man-machine interface sehingga pekerja dan mesin atau produk lainnya bisa berfungsi lebih efektif dan efisien sebagai sistem manusia-mesin yang terpadu (Wignjosoebroto, 2011).

Berdasarkan rekomendasi dari Occupational Safety and Health Administration (OSHA, 2000), tindakan ergonomik untuk mencegah adanya sumber penyakit melalui dua cara yaitu (1) rekayasa teknik, seperti desain stasiun kerja dan alat kerja; (2) rekayasa manajemen, seperti kriteria dan organisasi kerja. Berdasarkan pernyataan Goggins dkk. (2008) bahwa untuk mengurangi gangguan muskuloskeletal yang berhubungan dengan pekerjaan, maka perlu menerapkan program ergonomi secara komprehensif. Singh dan Arora (2010) memaparkan bahwa untuk mencegah dan mengurangi gangguan muskuloskeletal dilakukan dengan merancang alat dan peralatan dengan memperhatikan karakteristik ergonomi.

Dalam penelitian ini untuk menurunkan keluhan muskuloskeletal dilakukan evaluasi dan analisis ergonomi terhadap fasilitas kerja pengeringan ikan melalui rekayasa teknik yaitu dengan merancang ruang pengering berdasarkan data antropometri dan metode partisipatori dari pekerja wanita, karena proses pengeringan lebih didominasi oleh wanita. Antropometri merupakan kumpulan informasi tentang keadaan dan ciri-ciri fisik, dimensi, dan ukuran tubuh manusia yang diperlukan untuk mendesain sistem kerja, alat kerja, dan lingkungan kerja agar diperoleh suatu kondisi kerja yang aman dan nyaman.
Menurut Wignjosoebroto dkk. (2003), antropometri adalah satu kumpulan data numerik yang berhubungan dengan karakteristik fisik tubuh manusia, ukuran, dan kekuatan, serta penerapan dari data tersebut untuk penanganan masalah desain atau perancangan.

Aplikasi data antopometri dalam suatu desain dapat meliputi desain untuk orang ekstrim (orang dengan ukuran tubuh tidak normal meliputi orang dengan ukuran terkecil/terpendek atau orang dengan ukuran tertinggi/terbesar), desain untuk orang per orang, desain untuk kisaran yang dapat diatur (adjustable range) dengan menggunakan persentil 5 dan persentil 95 dari populasi dan desain untuk ukuran rerata menggunakan data persentil 50 (Sanders dan McCormick, 1993). Hal ini dilakukan karena setiap manusia berbeda satu dengan yang lainnya. Data antropometri digunakan untuk merancang tinggi rak paling bawah, rak paling atas dalam ruang pengering, dan posisi cerobong udara pada ruang pengering.

Partisipatori adalah semua yang akan terlibat terhadap pemecahan masalah harus dilibatkan sejak awal kegiatan. Masalah yang ditangani sesuai dengan hasil kesepakatan yang dapat diterima oleh semua pihak yang terlibat dalam pemecahan permasalahan. Menurut Manuaba (1999), partisipasi merupakan terlibatnya orang secara mental dan emosional terutama tenaga kerja ikut di dalam seluruh fase pembuatan atau diikutkan sejak awal dan diminta memberikan umpan balik. Dalam hal ini pihak yang dilibatkan adalah perajin ikan sebagai pengguna alat kerja.

\section{METODE PENELITIAN}

Ruang pengering dirancang berdasarkan data antropometri pekerja wanita seperti ditampilkan pada Tabel 1.

Tabel 1. Antropometri pekerja wanita untuk rancangan ruang pengering

\begin{tabular}{cll}
\hline No & Ukuran Bagian Tubul & \multicolumn{1}{c}{ Peruntukan } \\
\hline 1 & Tinggi tangan & Tinggi rak paling \\
& menggenggam & bawah \\
2 & Tinggi mata berdiri & $\begin{array}{l}\text { Tinggi maksimal } \\
\text { rak paling atas }\end{array}$ \\
& & Tinggi \\
3 & Tinggi jangkauan & maksimal \\
& atas & cerobong udara \\
\hline
\end{tabular}

Penggunaan data antropometri dalam mendesain suatu alat berdasarkan alur (1) menentukan dimensi tubuh yang penting dalam desain; (2) menetapkan populasi 
pengguna; (3) menghitung nilai persentil untuk setiap dimensi tubuh yang telah ditetapkan; (4) aplikasi pada desain alat. Tinggi tangan menggenggam (knuckle) adalah jarak vertikal dari lantai sampai metakarpal (jari tengah genggaman tangan). Tinggi mata berdiri adalah jarak vertikal dari lantai sampai sudut mata. Tinggi jangkauan atas adalah jarak vertikal dari lantai sampai titik tengah kepalan tangan. Dalam penelitian ini, aplikasi data antropometri untuk merancang ruang pengering menggunakan persentil 5 seperti ditunjukkan pada Rumus 1 .

$\bar{X}-(1,65 x \delta)$

$\bar{X}$ adalah rerata (mean) dan $\delta$ adalah simpangan baku (standar deviasi).

Besar sampel yang digunakan dalam pengukuran antropometri adalah 20 wanita perajin ikan. Penelitian ini adalah penelitian eksperimental, dengan rancangan sama subjek/Treatment by Subject Design. Sampel yang sama digunakan dalam pengukuran tingkat keluhan muskuloskeletal. Besar sampel dihitung berdasarkan rumus Colton, seperti ditunjukkan pada Rumus 2. Kesalahan tipe I yang diterima pada $\alpha=0,05$, dan kesalahan tipe II yang diterima pada $\beta=0,05$ (Colton, 1985).

$n=\left[\frac{\left(Z_{\alpha}-Z_{\beta}\right) \sigma}{\left(\mu_{1}-\mu_{0}\right)}\right]^{2}$

n merupakan besar sampel; $Z_{\alpha}$ adalah nilai $\mathrm{Z}$ untuk kesalahan tipe $\mathrm{I}=\alpha ; Z_{\beta}$ adalah nilai $\mathrm{Z}$ untuk kesalahan tipe $\|=\beta$; $\mu_{1}-\mu_{0}$ merupakan rata-rata perubahan yang diharapkan; $\mu_{0}$ adalah rerata variabel penelitian tanpa perlakuan (sebelum perbaikan); $\mu_{1}$ adalah rerata variabel penelitian dengan perlakuan (setelah perbaikan); $\sigma$ adalah standar deviasi; dan $\alpha$ ditetapkan 0,05 . Sampel memiliki umur antara 20 - 55 tahun. Rentangan umur dalam penelitian ini sudah berdasarkan kriteria sampel yang diambil dari populasi penelitian yaitu memenuhi kriteria inklusi. Kriteria inklusi meliputi bersedia sebagai subjek penelitian sampai selesai dengan menandatangani surat persetujuan kesediaan sebagai sampel; sehat jasmani dan rohani, serta tidak disertai cacat fisik; jenis kelamin wanita; umur 20-55 tahun; masa kerja minimal 6 bulan. Hal ini juga didukung dari hasil perhitungan indeks massa

tubuh (IMT) sampel sebesar 22,16 kg/m². Hasil ini sesuai dengan ketentuan Depkes (2003) bahwa kategori indeks massa tubuh normal dan status gizi baik untuk wanita adalah $17-23 \mathrm{~kg} / \mathrm{m}^{2}$

Observasi berupa pengukuran awal sebelum bekerja dan setelah selesai bekerja pada proses pengeringan tradisional maupun saat menggunakan ruang pengering berbasis ergonomi terhadap tingkat keluhan muskuloskeletal. Washing out period (WOP) diberikan kepada subjek atau sampel sebelum menggunakan ruang pengering. WOP diberikan selama satu hari untuk menghilangkan residual/carry over effects.

Alat uji berupa antropometer yang digunakan untuk mengukur antropometri/ dimensi tubuh pekerja yang diperlukan dalam merancang ruang pengering seperti ditunjukkan pada Tabel 1. Untuk mengukur tingkat keluhan muskuloskeletal dari pekerja digunakan metode NBM (Nordic Body Map). Aplikasi metode Nordic Body Map menggunakan lembar kerja berupa peta tubuh (body map). Metode ini digunakan karena caranya sangat sederhana, mudah dipahami, murah, dan memerlukan waktu yang sangat singkat. Menurut David dkk.( 2008), metode NBM sudah biasa dan secara luas digunakan dalam penelitian ergonomi karena biaya rendah, ada keterlibatan pekerja dan mudah dalam pengumpulan data.

Bahan yang digunakan dalam penelitian seperti disajikan pada Tabel 2.

Tabel 2. Spesifikasi teknis ruang pengering

Jumlah ruang pengering 1 unit
Jumlah rak dalam ruang

pengering

Luas tiap rak dalam

ruang pengering

Material ruang

pengering

Material rak dalam

ruang pengering

Material pintu ruang

pengering

Material rangka ruang

pengering

Pintu ruang pengering $\mathrm{mm}$
6 buah

$0,7505 \mathrm{~m}^{2}$

Pelat aluminium

$1,2 \mathrm{~mm}$

Bambu

Kaca bening 5

Aluminium

Kaca bening 5 $\mathrm{mm}$ dengan rangka aluminium

Metode partisipatori dilakukan dalam menentukan spesifikasi teknis ruang pengering seperti pada Tabel 2. Partisipatori merupakan masukan dari perajin ikan yang 
dilakukan berhubungan dengan rancangan alat agar material dalam pembuatan ruang pengering mudah diperoleh dan mudah dalam perawatan, serta kapasitas ruang pengering sesuai dengan kebutuhan para perajin ikan dalam bentuk usaha home industry.

\section{HASIL DAN PEMBAHASAN}

Hasil pengukuran data antropometri pekerja wanita meliputi rerata tinggi tangan menggenggam $68,66 \mathrm{~cm}$ dengan persentil 5 adalah 67,01 cm, agar semua subjek dapat memasukkan alas jemur ke rak paling bawah dalam ruang pengering dengan nyaman. Rerata tinggi mata berdiri $135,6 \mathrm{~cm}$ dengan persentil 5 adalah 123,2 cm, agar semua subjek dapat menjangkau dan mengamati hasil jemuran pada rak paling atas di dalam ruang pengering dengan nyaman. Rerata tinggi jangkauan atas $180,34 \mathrm{~cm}$ dengan persentil 5 adalah $170,24 \mathrm{~cm}$, agar semua subjek dapat menjangkau dan mengatur cerobong udara pada ruang pengering. Hasil pengukuran data antropometri pada wanita perajin ikan berdasarkan persentil 5 menghasilkan rancangan ruang pengering seperti disajikan pada Gambar 2. Dalam penelitian ini rak paling atas dalam ruang pengering digunakan 122,01 cm, hal ini menyesuaikan dengan jarak antara rak yang ada di dalam ruang pengering. Dengan menggunakan rancangan ruang pengering seperti pada Gambar 2, perajin ikan melakukan proses pengeringan dengan cara berdiri.

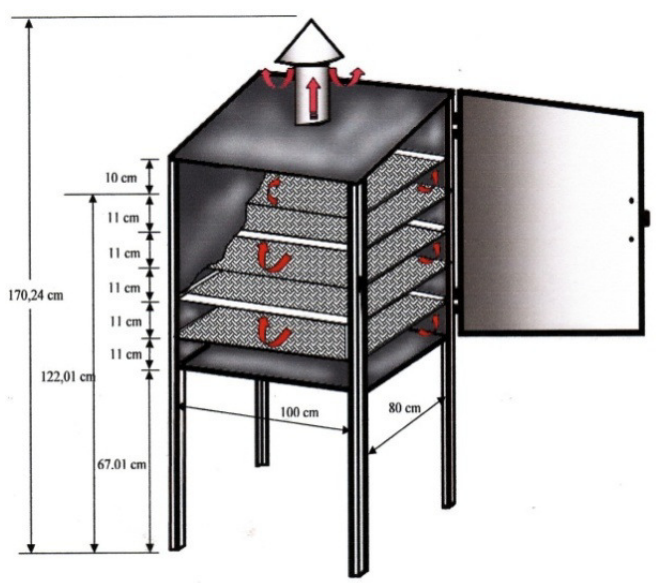

Gambar 2. Rancangan ruang pengering ikan berbasis ergonomi

Gambar 3 menyajikan perbandingan tingkat keluhan subjektif pada beberapa bagian tubuh antara sebelum dan sesudah intervensi ergonomi. Berdasarkan hasil pengolahan data kuesioner Nordic Body Map (NBM) memberikan gambaran terjadinya keluhan rasa sakit pada beberapa bagian tubuh perajin ikan seperti sakit/kaku di leher bagian atas, sakit bahu kanan, punggung, lengan atas kanan, pinggang, siku kanan, lengan bawah kanan, pergelangan tangan kanan, tangan kanan, paha, lutut, betis, pergelangan kaki, dan kaki. Pengukuran dilakukan berdasarkan kuesioner Nordic Body Map (NBM) seperti disajikan pada Lampiran 1 dengan A adalah skor 1, B skor 2, C skor 3, dan D skor 4 .

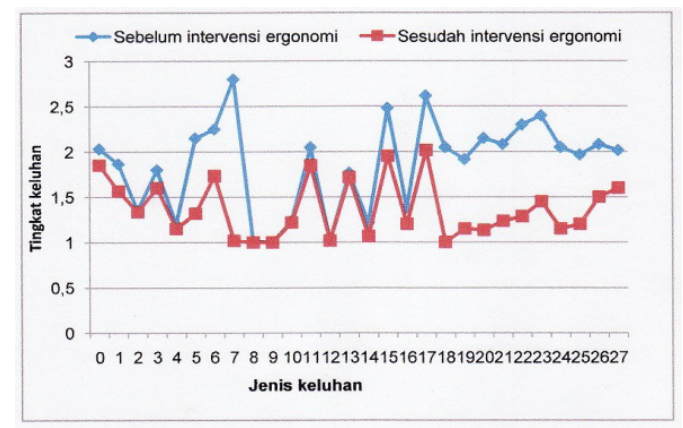

Gambar 3. Perbandingan tingkat keluhan subjektif sebelum dan sesudah intervensi ergonomi, jenis keluhan pada lampiran 1

Proses pengeringan ikan secara tradisional yang dilakukan sebelum intervensi ergonomi terjadi peningkatan rerata tingkat keluhan muskuloskeletal sebesar $74,17 \%$, yaitu dari $30,10 \pm 1,71$ saat sebelum bekerja menjadi 52,25 $\pm 1,03$ sesudah bekerja. Peningkatan tingkat keluhan muskuloskeletal dihitung berdasarkan keadaan sebelum bekerja dan sesudah bekerja Tingginya peningkatan tingkat keluhan muskuloskeletal diakibatkan sikap kerja yang tidak alamiah. Hal ini mengakibatkan pembebanan pada otot terutama pinggang, punggung, leher, badan membungkuk, bahu, lutut, yang pada akhirnya menimbulkan kelelahan otot. Keluhan muskuloskeletal yang terjadi pada perajin ikan mempengaruhi kesehatan pekerja yang berdampak pada rendahnya tingkat produktivitas. Hal ini sesuai dengan pernyataan Zheltoukhova dkk. (2012) bahwa dampak keluhan muskuloskeletal terhadap kemampuan individu untuk bekerja memiliki implikasi bagi pengeluaran untuk kesehatan dan kesejahteraan.

Setelah dilakukan intervensi ergonomi, peningkatan rerata tingkat keluhan muskuloskeletal sebesar 27,67\%, yaitu sebelum bekerja sebesar 29,80 $\pm 1,15$ dan sesudah bekerja sebesar $38,30 \pm 1,30$. Hasil ini 
jauh lebih kecil jika dibandingkan dengan rerata peningkatan keluhan muskuloskeletal pada proses pengeringan ikan secara tradisional. Hal ini sebagai dampak dari penggunaan alat kerja ergonomis yang dapat merubah sikap kerja tidak alamiah dari pekerja. Dengan terjadinya perubahan sikap kerja menurunkan tingkat keluhan muskuloskeletal pekerja. Hal ini sesuai dengan paparan Qutubuddin dkk. (2012) bahwa dengan ergonomi dapat mengurangi potensi kesehatan yang buruk di tempat kerja yaitu MSDs seperti rasa sakit dan nyeri pergelangan tangan, siku, bahu, dan punggung.

Intervensi ergonomi yang dilakukan melalui perbaikan alat kerja dalam penelitian ini memberikan pengaruh terhadap terjadinya perubahan sikap kerja dari jongkok, jongkok sambil bergeser, dan membungkuk (Gambar 1) menjadi sikap kerja berdiri seperti ditampilkan pada Gambar 4.

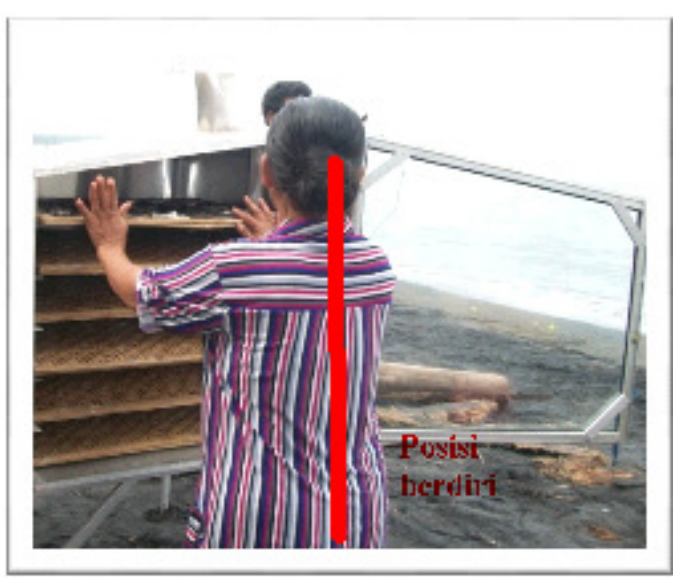

Gambar 4. Sikap kerja berdiri

Hal ini dikuatkan rekomendasi dari (OSHA, 2000) bahwa untuk mengatasi keluhan muskuloskeletal adalah dengan tindakan ergonomi melalui rekayasa teknik yang dilakukan melalui substitusi yaitu mengganti alat/bahan lama dengan alat/bahan baru yang aman, sehingga menyempurnakan proses produksi. Rekayasa teknik yang dilakukan dalam penelitian ini yaitu melalui rancangan ruang pengering berbasis ergonomi terbukti mampu menurunkan tingkat keluhan muskuloskeletal perajin ikan.

\section{KESIMPULAN}

Penerapan ergonomi pada proses pengeringan memberikan dampak yang signifikan pada wanita perajin ikan.
Berdasarkan hasil pengujian dapat disimpulkan sebagai berikut.

1. Dimensi rancangan ruang pengering berdasarkan data antropometri dengan persentil 5 meliputi tinggi rak paling bawah dalam ruang pengering adalah 67,01 cm; tinggi rak paling atas dalam ruang pengering adalah $122,01 \mathrm{~cm}$; dan tinggi cerobong udara adalah $170,24 \mathrm{~cm}$.

2. Penerapan metode partisipatori menghasilkan rancangan ruang pengering dengan material yang murah, mudah dipindahkan, dan mudah memperoleh bahan seperti aluminium, kaca, dan bambu. Penerapan metode ini diharapkan perbaikan yang dilakukan menjadi lebih sustain.

3. Tingkat keluhan muskuloskeletal menurun sebesar $26,70 \%$ yaitu dari $52,25 \pm 1,03$ sebelum intervensi ergonomi menjadi $38,30 \pm 1,30$ setelah intervensi ergonomi.

\section{DAFTAR PUSTAKA}

Adiputra, N., 2004, Ergonomi, Disampaikan dalam Pelatihan Upaya Kesehatan Kerja Tenaga Kesehatan Kabupaten/Kota dan Puskesmas Propinsi Bali, Denpasar, 23-27 Maret dan 29 Maret-2 April.

Bridger, R.S., 2003, Introduction to Ergonomics, 2nd edition, Taylor \& Francis, London and New York.

Colton, T., 1985, Statistik Kedokteran, Gadjah Mada University Press, Yogyakarta.

David, G., Wood, V., Li, G., Buckle, P., 2008, The development of the quick exposure check (QEC) for assessing exposure to risk factors work-related musculoskeletal disorders, Journal of Applied Ergonomics, vol. 39, no. 1, 5769.

Depkes RI., 2003, Survey Indeks Massa Tubuh (IMT) Pengumpulan Status Gizi Orang Dewasa Berdasarkan IMT, Direktorat Bina Gizi Masyarakat.

Goggins, R.W., Spielholz, P., Nothstein, G.L., 2008, Estimating the effectiveness of ergonomics interventions through case studies: implications for predictive costbenefit analysis. Journal of Safety Research, Elsevier, vol. 39, 339-344.

Kroemer, K.H.E., Grandjean, E., 2000, Fitting the Task to the Human, A Textbook of Occupational Ergonomics, $5^{\text {th }}$ edition, Taylor\&Francis, Philadelphia.

Manuaba, A., 1999, Penerapan pendekatan ergonomi partisipasi dalam meningkatkan kinerja industri, 
Disampaikan dalam Seminar Nasional Ergonomi, Surabaya, 23 Nopember.

OSHA, 2000, Ergonomic: the study of work, Occupational Safety and Health Administration, U.S. Department of Labor.

Pheasant, S., Haslegrave, C.M., 2006, Bodyspace, Antropometry, Ergonomics and the Design of Work, Taylor \& Francis London.

Plog, B.A., Quinlan, P.J., 2002, Fundamentals of Industrial Hygiene, Fifth edition, National Safety Council, USA.

Qutubuddin, S.M., Hebbal, S.S., Kumar, A.C.S., 2012, Computer assisted system for enhancing the application of ergonomics in manufacturing systems, International Journal of Ergonomics (IJEG), vol. 2, no. 1, 1-11.

Sanders, M.S., McCormick, E.J., 1993, Human Factors in Engineering and Design, Seventh Edition, McGraw Hill Publishing Company Ltd, New York.

Singh, S., Arora, R., 2010, Ergonomic intervention for preventing musculoskeletal disorders among farm women, J Agri Sci, vol. 1, no. 2, 61-71.

Susila, IG.N., 2002, Gangguan muskuloskeletal, Udayana Medical Journal, vol. 33, no. 120, 90-93.

Tarwaka, 2011, Ergonomi Industri: Dasardasar Pengetahuan Ergonomi dan Aplikasi di Tempat Kerja, Harapan Press, Surakarta.

Wignjosoebroto, S., 2011, Ergonomi industri dalam pendidikan terintegrasi: pendekatan ergonomi menjawab problematika industri, Disampaikan dalam Acara Semiloka Linearitas Ergonomi, Fakultas Kedokteran, Universitas Udayana, Denpasar, 21 April.

Wignjosoebroto, S., Partiwi, S.G., Hanafi, A., 2003, Modifikasi rancangan mesin perontok padi dengan pendekatan ergonomi-antropometri, Prosiding Seminar Nasional Ergonomi, Perhimpunan Ergonomi Indonesia (PEI) dan Fakultas Teknologi Pertanian Universitas Gadjah Mada, Yoyakarta, 13 September.
Zheltoukhova, K., O`Dea, L., Bevan, S., 2012, Taking the strain: the impact of musculoskeletal disorders on work and home life, Lancaster University. 


\section{LAMPIRAN}

Lampiran 1

\section{KUESIONER NORDIC BODY MAP}

(Tulislah identitas saudara dan coret yang tidak perlu)

1. Nama

2. Umur/Tgl Lahir

3. Pendidikan Terakhir

4. Status

:...........................

5. Pengalaman Kerja

: SD/SMP/SMA/AKADEMI/UNIVERSITAS

: Kawin/Belum Kawin

KUESIONER BODY MAP

(Jawablah pertanyaan berikut ini dengan memberi tanda $(X)$ pada kolom disamping pertanyaan yang sesuai dengan kondisi/perasaan saudara)

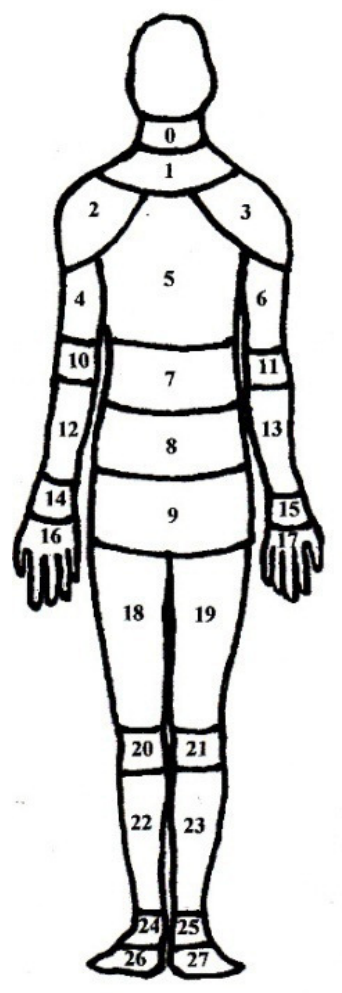

\begin{tabular}{|r|l|l|l|l|l|}
\hline \multirow{2}{*}{ NO } & \multicolumn{1}{|c|}{ JENIS KELUHAN } & \multicolumn{3}{|c|}{ TINGKAT } \\
\cline { 3 - 5 } & & KELUHAN \\
\hline & & Sakit/kaku di leher bagian atas & B & C & D \\
\hline 1 & Sakit/kaku di leher bagian bawah & & & & \\
\hline 2 & Sakit di bahu kiri & & & \\
\hline 3 & Sakit di bahu kanan & & & \\
\hline 4 & Sakit pada lengan atas kiri & & & & \\
\hline 5 & Sakit di punggung & & & & \\
\hline 6 & Sakit pada lengan atas kanan & & & & \\
\hline 7 & Sakit pada pinggang & & & & \\
\hline 8 & Sakit pada bokong & & & & \\
\hline 9 & Sakit pada pantat & & & & \\
\hline 10 & Sakit pada siku kiri & & & & \\
\hline 11 & Sakit pada siku kanan & & & & \\
\hline 12 & Sakit pada lengan bawah kiri & & & & \\
\hline 13 & Sakit pada lengan bawah kanan & & & & \\
\hline 14 & Sakit pada pergelangan tangan kiri & & & & \\
\hline 15 & Sakit pada pergelangan tangan kanan & & & & \\
\hline 16 & Sakit pada tangan kiri & & & & \\
\hline 17 & Sakit pada tangan kanan & & & & \\
\hline 18 & Sakit pada paha kiri & & & & \\
\hline 19 & Sakit pada paha kanan & & & & \\
\hline 20 & Sakit pada lutut kiri & & & & \\
\hline 21 & Sakit pada lutut kanan & & & \\
\hline 22 & Sakit pada betis kiri & & & \\
\hline 23 & Sakit pada betis kanan & & & \\
\hline 24 & Sakit pada pergelangan kaki kiri & & & & \\
\hline 25 & Sakit pada pergelangan kaki kanan & & & & \\
\hline 26 & Sakit pada kaki kiri & & & \\
\hline 27 & Sakit pada kaki kanan & & & \\
\hline
\end{tabular}

Keterangan :
A: Tidak sakit
B: Agak sakit
C: Sakit
D: Sakit sekali 